\title{
A study to evaluate the effectiveness of foot reflexology on depressionamong older adults in selected old age homes. \\ *Sirumalar.J
}

\section{Abstract}

Objectives- To evaluate the effectiveness of foot reflexology on depression among older adults staying in the old age homes. Method-One group pre test and post test design. Result-It revealed that the calculated " $t$ " value (23.388) was much higher than the table value at 0.01 level of significance with 29 degrees of freedom,. Conclusion- The study concluded that foot reflexology is a non pharmacological, complementary, and alternative therapy to manage thedepression among depressed older adults.

Keywords: Foot Reflexology, Older Adults, Depression, Old age Homes.

\section{Introduction}

Depression is a hushed killer, which is very hard to diagnose among older adults. Older adults suffer from number of physical and psychological illness, one of the important psychiatric illness is depression. The typical symptoms of depression includes, decreases in energy and concentration, disturbed sleep and loss of appetite, somatic complaints, low self esteem, feeling of hopelessness and suicidal tendencies.2 Foot Reflexology is applying pressure and massaging the foot that improves blood circulation and flush out the lactic and crystals that are settled in the feet, then they can be reabsorbed and eliminated from the body.5 These points are under the big toe on the ball of the foot and, towards the inside. Points on the hand and feet that corresponds to the heart, chest, solar plexus, lungs and upper limbs will be applied pressure to alleviate the symptoms of depression. Applyingpressure will develop the discharge of feel

good chemical called endorphin will relieve the stress that has big impact ondepression. ${ }^{3}$ Assessment on level of depression before and after foot reflexology among the older adults. The level of depression was categorized into Normal, Mild and Severe based on the scale given by

Geriatric depression scale. The mean and mean percentage score on level of depression was assessed during the study period to check if the intervention had a role in reducing depression among the older adults.

\section{Objectives}

- To assess the level of depression among older adults staying in old age homes before and after administration of foot reflexology.

- To evaluate the effectiveness of foot reflexology on depression among older 
adults staying in the old age homes.

- To associate the level of depression among the older adults with selected demographic variables.

\section{Data Analysis}

Table 1: Assessment on Level of Depression among Older Adults $\mathrm{N}=30$

\begin{tabular}{|l|c|c|c|c|c|c|}
\hline \multirow{2}{*}{ Level } & \multicolumn{2}{|c|}{ Before intervention } & \multicolumn{3}{|c|}{ After intervention } \\
\cline { 2 - 7 } & N & Mean & $\begin{array}{c}\text { Mean } \\
\%\end{array}$ & N & Mean & $\begin{array}{c}\text { Mean } \\
\%\end{array}$ \\
\hline$(\mathbf{0}-\mathbf{9})$ & - & - & - & 5 & 8.6 & 29 \\
\hline$(\mathbf{1 0}-\mathbf{1 9})$ & 18 & 17.33 & 58 & 25 & 11.68 & 39 \\
\hline $\mathbf{( 2 0}-\mathbf{3 0})$ & 12 & 21.17 & 71 & - & - & - \\
\hline
\end{tabular}

The above table described the level of depression of older adults before and after foot reflexology. The table revealed that $12(40 \%)$ of the older adults had severe depression (71\%) while 18(60\%) had mild depression (58\%) before foot reflexology. After foot reflexology the level of depression decreased from severe depression to mild (39\%) and normal (29\%) levels. Thus the foot reflexology had reduced the level of depression.

Analysis on the level of depression beforeand after foot reflexology

The level of depression among the older adults reveals that there was a decrease in the mean score after foot reflexology. To prove the significance in the result paired't' - test was applied. The above table reveals that the calculated " $t$ " value was much higher than the table value at 0.01 level of significance with 29 degrees of freedom. Thus the research hvpothesis before and after the foot reflexologyamong the older adults was accepted.Thus the inferential statistical methodproves that the difference in the meanscores showed a significant change in thelevel of depression. Thus foot reflexologywas effective in reducing the depressionamong the older adults.

\section{Recommendations}

- Nurses can be appointed as regular therapist to conduct foot reflexology sessions in community settings and old age homes. Useful interventions such as entertainment technique, like yoga, meditation can be taught by the nurses to the older adults

- Nurses should make effort to engage all the inmates in attending social activities and special functions

- Positive validation, rewards, support in doing minor activities as much as possible to be enforced.

\section{Conclusion}

The study concluded that foot reflexology is a non pharmacological, complementary and alternative therapy to manage the depression among depressed older adults.

\section{References}

1. Kaplan and Sadock. Synopsis of Psychiatry, Behavioral sciences / clinical Psychiatry.10th ed. Lippincott Publishers; 2008.

2. Kothari C.R. Research Methodology, Methods and techniques. 2nd ed. Vishay Prakash, Publishers; 2001. 
3. Boyd MA. Psychiatric Nursing, Contemporary Practice. 3rded. Lippincott Publications; 2005

4. Sheila Videbeck. L. Psychiatric Mental health Nursing. 3rded. Williams\& Wilkins publishers; 2006.

5. Aravind, V.K. \& Krishna ram V.D. A study of depression in old age individuals. Indian journal of psychiatry. 2007 ( 49);28-34

6.Kulothungam. Validation of Geriatric Depression Scale. Indian journal of psychiatry.2010; 52(3) 254.

7.Lee, Y.M. Effect of Self-Foot ReflexologyMassage on Depression, Stress Responsesand Immune Functions of Middle AgedWomen. J Korean Acad AdultNursing.2006; 336 (1) 179-88.

8.Levin, C.A, Wei W, Akincigil A, Lucas J.A, Bilder S, Crystal S. Prevalence and treatment of diagnosed depression among elderly nursing home residents in Ohio. Age Ageing. 2007;36 (5), 562568.

\section{Answer for last Issue (sep-dec15)}

\begin{tabular}{|l|l|l|l|l|l|l|l|}
\hline P & R & O & T & E & I & N & S \\
\hline E & I & S & N & G & M & I & O \\
\hline L & C & M & E & G & M & M & D \\
\hline L & K & O & D & U & U & A & I \\
\hline A & E & S & I & A & N & T & U \\
\hline G & T & I & X & V & E & I & M \\
\hline R & S & S & O & A & & V & \\
\hline
\end{tabular}

